\title{
Endoscopic ultrasound (EUS) and the management of pancreatic cancer
}

Muhammad Nadeem Yousaf (1) , 1,2,3,4 Fizah S Chaudhary, ${ }^{2,3,4}$ Amrat Ehsan, ${ }^{2,3,4}$ Alejandro L Suarez, ${ }^{1}$ Thiruvengadam Muniraj, ${ }^{1}$ Priya Jamidar, ${ }^{1}$ Harry R Aslanian, ${ }^{1}$ James J Farrell ${ }^{1}$

To cite: Yousaf MN, Chaudhary FS, Ehsan A, et al. Endoscopic ultrasound (EUS) and the management of pancreatic cancer. BMJ Open Gastro 2020;7:e000408. doi:10.1136/ bmjgast-2020-000408

Received 23 March 2020 Revised 21 April 2020 Accepted 22 April 2020

\section{Check for updates}

(c) Author(s) (or their employer(s)) 2020. Re-use permitted under CC BY-NC. No commercial re-use. See rights and permissions. Published by BMJ.

${ }^{1}$ Department of Medicine, Section Digestive Diseases, Yale University School of Medicine, New Haven, Connecticut, USA ${ }^{2}$ Department of Internal Medicine, MedStar Union Memorial Hospital, Baltimore, Maryland, USA

${ }^{3}$ Department of Internal Medicine, MedStar Good Samaritan Hospital, Baltimore, Maryland, USA

${ }^{4}$ Department of Internal Medicine, MedStar Franklin Square Medical Center, Baltimore, Maryland, USA

Correspondence to Dr Muhammad Nadeem Yousaf; muhammad.n.yousaf@medstar. net

\section{ABSTRACT}

Pancreatic cancer is one of the leading causes of cancerrelated mortality in western countries. Early diagnosis of pancreatic cancers plays a key role in the management by identification of patients who are surgical candidates. The advancement in the radiological imaging and interventional endoscopy (including endoscopic ultrasound (EUS), endoscopic retrograde cholangiopancreatography and endoscopic enteral stenting techniques) has a significant impact in the diagnostic evaluation, staging and treatment of pancreatic cancer. The multidisciplinary involvement of radiology, gastroenterology, medical oncology and surgical oncology is central to the management of patients with pancreatic cancers. This review aims to highlight the diagnostic and therapeutic role of EUS in the management of patients with pancreatic malignancy, especially pancreatic ductal adenocarcinoma.

\section{INTRODUCTION}

Pancreatic cancer is the fourth leading causes of cancer-related death in the USA with an estimated of 55600 (30 400 men and 27200 women) new cases, and 47050 (24 640 men and 22410 women) deaths in 2020. ${ }^{1}$ The highest incidence rate is reported in North America and Europe while lowest in Africa and South Central. ${ }^{2}$ The common risk factors for pancreatic cancer are smoking, positive family history, genetics, alcohol consumption, obesity, diabetes, diet and physical inactivity. $^{3-5}$ Overall 5-year survival rate is $8 \%$ (ranging from $2 \%$ to $9 \%$ ). ${ }^{6-9}$ The poor outcome of the disease is due to metastatic or local advancement of disease at time of diagnosis in the majority of patients. The introduction of newer medical therapies (including neoadjuvant chemotherapy approaches) and improvement of surgical techniques for resection of pancreatic cancer has had modest impact on the outcome of disease in last decade. Because of the rising disease burden, there is an increasing emphasis on early identification of pancreatic cancers and premalignant pancreatic lesions in high-risk individuals. Advancement in technology to improve both non-invasive imaging (CT scan, MRI, nuclear imaging) and minimally invasive imaging (endoscopic ultrasound (EUS), endoscopic retrograde cholangiopancreatography (ERCP)) plays an important role in early detection of pancreatic cancers. Specifically, EUS has a central role in diagnosis, staging, palliative therapy and increasingly the therapy of pancreatic cancers.

\section{ENDOSCOPIC ULTRASOUND}

EUS is an endoscopic imaging modality which provides a detailed and high-resolution spatial imaging of the pancreas compared with CT or MRI through the addtion of an ultrasound transducer on the tip of the flexible endoscope. ${ }^{10}$ Linear EUS performs imaging in the same plane as shaft of the endoscope, whereas with radial EUS circumferential viewing can be obtained in the plane perpendicular to the shaft of the endoscope. EUS provides the added advantage of high resolution imaging for the identification and evaluation of small pancreatic masses and cysts by taking magnified imaging due to close proximity of EUS transducer to the pancreas by positioning the transducer in the gastro-oesophageal junction (GOJ), bulb and second portion of the duodenum, and by eliminating the effect of intestinal gas and fat.

\section{EUS-GUIDED DIAGNOSTIC INTERVENTIONS EUS evaluation of solid pancreatic mass lesions}

Because of the rising incidence of pancreatic cancer and limited treatment, there is increased emphasis on early detection of pancreatic cancer. Pancreatic intraepithelial neoplasm (PanIN) is a preinvasive form of pancreatic cancer, has potential for malignant transformation to pancreatic adenocarcinoma. It has been suggested that early PanIN 1 lesions can progress to adenocarcinoma in $1.3 \%$ in women and $1.5 \%$ in men 
over a lifetime period, and that more advanced PanIN 3 lesions can progress to adenocarcinoma over an estimated period of 12.3 years in women and 11.3 years in men. ${ }^{11}$ However, due to lack of optimum screening tests including the ability to visualize these PanIN lesions, early detection of pancreatic lesions is challenging. Pancreatic cancer screening of the general population is not recommended because of low disease prevalence. ${ }^{12}$ The screening of high-risk populations including those with familial pancreatic cancer and those with known germline genetic mutations for the development of pancreatic cancers (eg, BRCA 2, BRCA1, p16) are the potential targets. ${ }^{13}$ Non-invasive imaging (such as MRI and CT scan) and minimally invasive imaging with EUS are the main screening tools for these high-risk population. ${ }^{14151315-17}$ Early data suggest a survival benefit to diagnosing early pancreatic cancer within these high surveillance programs.
EUS is more sensitive, specific and accurate in the detection of pancreatic lesions than high-quality crosssectional imaging. Numerous studies $(n=23)$ have shown high sensitivity (92\%-100\%), specificity (89\%-100\%) and accuracy $(86 \%-99 \%)$ of EUS in the detection of pancreatic malignancies which is higher than that of CT scan, particularly with small diameter pancreatic lesions (table 1). ${ }^{10-40}$ The additional advantages of EUS over cross-sectional images are especially for small pancreatic masses $(0.5-2 \mathrm{~cm})$ and the ability to perform EUS-guided fine needle aspiration (EUS-FNA) or fine needle biopsy (EUS-FNB) is helpful for confirmation of tissue diagnosis and staging of tumor (eg, by obtaining the biopsy of metastatic liver lesions and lymph nodes ${ }^{1041}$ (table 1 ).

Identification of small pancreatic cancers is challenging in the presence of chronic pancreatitis where heterogeneous echogenicity of pancreatic tissue can mask hypoechoic malignant lesions which may result in

Table 1 Prospective/retrospective studies on diagnostic performance of EUS versus CT for detection of pancreatic malignancy

\begin{tabular}{|c|c|c|c|c|c|}
\hline Study & Year of study & $\begin{array}{l}\text { Total no of } \\
\text { patients }\end{array}$ & $\begin{array}{l}\text { Sensitivity, EUS } \\
\text { versus CT (\%) }\end{array}$ & $\begin{array}{l}\text { Specificity, EUS } \\
\text { versus CT (\%) }\end{array}$ & $\begin{array}{l}\text { Accuracy, EUS } \\
\text { versus CT (\%) }\end{array}$ \\
\hline Du et $a l^{17}$ & 2017 & 68 & 98 vs $73^{*}$ & NA & NA \\
\hline Kamata et $a l^{18}$ & 2014 & 35 & 100 vs $56^{*}$ & 100 vs 100 & NA \\
\hline Kitano et $a l^{19}$ & 2012 & 277 & 91 vs $71^{*}$ & 94 vs 92 & NA \\
\hline Sakamoto et $a^{20}$ & 2008 & 156 & 94 vs $50^{*}$ & NA & NA \\
\hline Jemma et $a l^{21}$ & 2008 & 42 & 100 vs $88^{*}$ & 89 vs 83 & NA \\
\hline Kitano et $a l^{22}$ & 2004 & 65 & 95 vs $68^{*}$ & NA & NA \\
\hline Agarwal et $a l^{23}$ & 2004 & 81 & 100 vs $75^{\star}$ & NA & 94 vs $74^{*}$ \\
\hline DeWitt et $a l^{9}$ & 2004 & 120 & 98 vs $86^{\star}$ & NA & NA \\
\hline Rivadeneira et $a^{24}$ & 2003 & 48 & 100 vs $68^{*}$ & 75 vs $50^{*}$ & 98 vs $67^{*}$ \\
\hline Mertz et $a l^{25}$ & 2000 & 35 & 93 vs $53^{*}$ & NA & 86 vs $49^{*}$ \\
\hline Gress et $a l^{26}$ & 1999 & 151 & 100 vs 74 & NA & NA \\
\hline Harrison et $a l^{27}$ & 1999 & 19 & 100 vs $50^{*}$ & NA & 98 vs $63^{*}$ \\
\hline Midwinter et $a{ }^{28}$ & 1999 & 48 & 97 vs 76 & NA & NA \\
\hline Legmann et al ${ }^{29}$ & 1998 & 30 & 100 vs 92 & NA & 93 vs 93 \\
\hline Sugiyama et $a l^{30}$ & 1997 & 54 & 96 vs $89^{*}$ & NA & NA \\
\hline Howard et al ${ }^{31}$ & 1997 & 21 & 75 vs $63 \dagger$ & 77 vs 100† & 76 vs $86 \dagger$ \\
\hline Melzer et $a l^{32}$ & 1996 & 12 & 100 vs 83 & NA & 100 vs 76 \\
\hline Nakaizumi et $a l^{33}$ & 1995 & 232 & 94 vs $65^{\star}$ & 97 vs 94 & 96 vs $88^{*}$ \\
\hline Marty et $a /^{34}$ & 1995 & 37 & 92 vs 63 & NA & NA \\
\hline Müller et $a l^{35}$ & 1994 & 49 & 94 vs $69 \dagger$ & 100 vs 64 & 96 vs 67 \\
\hline Palazzo et $a /^{37}$ & 1993 & 64 & 96 vs $69 \dagger$ & 73 vs 53 & 91 vs $66^{*}$ \\
\hline Yasuda et $a l^{38}$ & 1993 & 29 & 100 vs $72 \dagger$ & NA & $\begin{array}{l}\text { Duodenal Invasion: } \\
83 \text { vs } 33 \\
\text { Gastric invasion: } 79 \\
\text { vs } 38\end{array}$ \\
\hline Rösch et $a l^{39}$ & 1991 & 102 & 99 vs 77 & 100 vs 53 & NA \\
\hline
\end{tabular}

*Statistically significant data.

†Statistics are not available.

EUS, endoscopic ultrasound; NA, not applicable. 
missed diagnosis. ${ }^{41}$ Patients with chronic pancreatitis are at increased risk of developing pancreatic cancer. EUS imaging finding supporting a diagnosis of pancreatic cancer in the setting of chronic pancreatitis are mass size above $2 \mathrm{~cm}$, irregular dilation of the main pancreatic duct and branch duct, vascularity of mass, absence of cysts within mass and presence of lymphadenopathy and vascular invasion. ${ }^{42} 43$

To discriminate pancreatic cancers from inflammatory pancreatic masses, conventional EUS evaluation alone is often not enough despite high sensitivity and specificity over cross-sectional imaging. The introduction of contrast-enhanced (CE) EUS and EUS elastography may improve the evaluation of pancreatic cancers even in the presence of concomitant autoimmune pancreatitis (AIP) or chronic pancreatitis. ${ }^{44}$ CE-EUS is a technique which combines high-resolution endoscopy ultrasound waves with intravenous contrast. CE-EUS generates an acoustic signal when ultrasound waves interact with oscillating microbubbles in the intravenous contrast. These acoustic signals help in the assessment of vascularity of pancreatic masses in addition to providing information about echogenicity of lesions. CE-EUS features such as isoenhancement or hypoenhancement, arterial irregularity and absent venous vasculature within a mass favours pancreatic ductal adenocarcinoma (PDAC) while hyperenhanced lesions with the preserved architecture of both arterial and venous microvasculature indicate chronic pancreatitis. ${ }^{45-47}$ CE-EUS can reliably differentiate pancreatitis from pancreatic cancer with sensitivity, specificity, positive predictive value and negative predictive value) of $91 \%, 93 \%, 100 \%$ and $88 \%$ respectively. ${ }^{4} 49$ It also helps in differentiating pancreatic cystic lesions such as serous cystadenoma (enhancement of intracystic septation), mucinous cystic neoplasm (MCN) (irregular enhancement of intralesional septum and nodule), malignancy intraductal papillary mucinous neoplasms (IPMN) (invasive and papillary mural nodule) and benign IPMN (polypoidal non-invasive papillary nodule). ${ }^{47}$ A metaanalysis on 19 studies has shown pooled sensitivity $91 \%$, specificity $86 \%$ for the diagnosis of focal pancreatic masses or PDAC..$^{50}$

Elastography is a newer non-invasive technique to evaluate stiffness (elasticity) of soft tissue. EUS transducer sends a shearing wave through the pancreas and generates an elastogram by calculating velocity faced by shearing wave while passing through soft tissue. EUS elastography works as an adjunct to EUS-FNA which may help in the differentiation of malignant from non-malignant masses. The diagnostic yield of EUS elastography in the differentiation of solid pancreatic cancers is variable, with three meta-analyses showing a $95 \%-97 \%$ pooled sensitivity and $67 \%-76 \%$ specificity. ${ }^{51-53}$

An algorithm for the evaluation and management of patients with suspected pancreatic adenocarcinoma based on current guidelines is shown in figure $1 .{ }^{15}$ EUSFNA should be performed whenever possible for resectable pancreatic cancers to rule out alternative diagnosis.

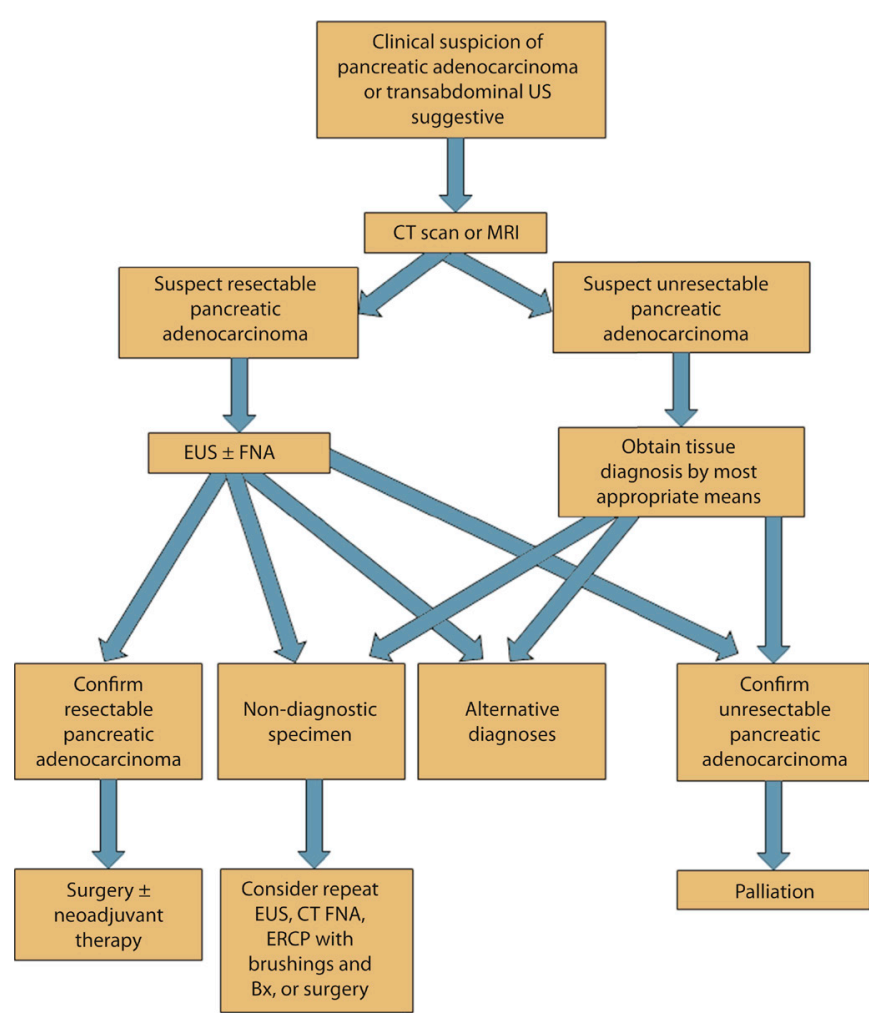

Figure 1 Algorithm for the evaluation and management of patients with suspected pancreatic adenocarcinoma (courtesy of American society of gastrointestinal endoscopy (ASGE) practice guidelines). EUS, endoscopic ultrasound; ERCP, endoscopic retrograde cholangiopancreatography; FNA, fine-needle aspiration.

It could be difficult to differentiate from pancreatic neoplasm and to confirm tissue diagnosis if needed in patients who are unresectable. In addition, having a tissue diagnosis of PDAC for resectable disease allows for possible neoadjuvant therapy options.

\section{EUS evaluation of pancreatic cystic lesions}

With the advancement of cross-sectional imaging, the detection rate of incidental pancreatic cyst has increased. The most common incidental pancreatic cystic lesions include mucinous cysts (eg, MCN and IPMNs) pseudocysts and serous cystadenomas. ${ }^{54}$ Mucinous cystic lesions (which are considered premalignant and occasionally malignant) need to be differentiated from nonmucinous lesions, as they often carry different prognoses and management. EUS and cross-sectional imaging both MRI/CT scans are generally considered to be complimentary for the evaluation of pancreatic cysts. Although MRI is considered superior in the evaluation of pancreatic cystic lesions, a distinct advantage of EUS (especially with improved image resolution) is the ability to sample pancreatic cyst fluid for both cytology and tumor markers including carcinoembryonic antigen (CEA) and DNA mutational analysis. ${ }^{5-59}$ Under current guidelines, EUS is increasingly reserved for pancreatic cysts with high-risk stigmata or worrisome features where it may impact on 
diagnostic workup as well as stratifying patients for either surveillance or surgical resection. ${ }^{1660}$

\section{Staging of pancreatic cancers}

EUS is a useful modality for the staging of pancreatic cancers in patients with suspected malignancy and assisting in determining surgically resectable lesions. Due to their widespread availability and non-invasive nature, imaging with CT or MRI remains the first-line imaging of choice to perform staging of pancreatic malignancy. For example, advanced cross-sectional imaging from a multidetector CT allows the acquisition of pancreatic arterial phase, pancreatic parenchymal phase and portal venous phase imaging. Pancreatic parenchymal phase and portal venous phase are very useful tools in the identification and precise preoperative vascular staging of pancreatic cancers. ${ }^{61}$ However, EUS is still an effective tool for evaluation of vascular invasion of tumor, for example, portal vein, superior mesenteric artery (SMA) and superior mesenteric vein notably in patients with small size tumor and in those who cannot undergo CE CT or MRI due to other medical reasons. ${ }^{62}{ }^{63}$ EUS also provides additional objective data on perivascular cuffing, assessment of liver masses and local lymph nodes for the staging of pancreatic cancers, especially in individuals who have undergone prior chemotherapy treatment. ${ }^{4164}$

\section{EUS-guided FNA}

Indications

While CT and MRI imaging may identify a pancreatic mass and strongly suggest an underlying malignancy, pathological diagnosis is necessary to determine the benign or malignant nature of the mass. In the era prior to EUS, the tissue diagnosis of pancreatic masses used to be established by acquisition of tissue specimen by abdominal ultrasound, or CT-guided percutaneous biopsy, or ERCP-guided bile duct brush cytology, or on surgical exploration. The sensitivity of ERCP brush cytology is approximately $30 \%$ in the diagnosis of pancreatic malignancy. ${ }^{65}$ The utility of this approach is limited due to high rate of post ERCP pancreatitis and technical difficulty in obtaining cytology sample especially in case of benign stricture of the pancreatic duct. ${ }^{65}$ Currently, EUS-FNA biopsy is preferred over these other methods to obtain tissue and for establishing a diagnosis of pancreatic cancer. In case of pancreatic cystic lesions, EUS-FNA helps to distinguish pancreatic cysts with malignant potential (eg, MCN and IPMN) from other cystic lesions without malignant potential (eg, serous cystadenoma). Cyst fluid analysis for cytology, mucin containing goblet cells, tumor markers (CEA), DNA genetic mutation analysis (K-ras), and amylase may help to establish the diagnosis of pancreatic cystic lesions. Recent developments allow for the acquisition of cyst wall tissue by using a through-the-needle biopsy with moray forceps, in addition to the use of through-the-needle confocal microscope probes.
Technical feasibility considerations

EUS-FNA is the technique to obtain tissue for cytological evaluation which can be performed with a linear echoendoscope to target the pancreatic lesion under direct visualization. Tissue acquisition from uncinate, head and neck lesions can be performed by positioning endoscope in the duodenal bulb or second portion of duodenum while tissue from neck, body and tail lesions can be acquired by positioning endoscope in GOJ or proximal stomach. EUS-guided FNA needle targets the pancreatic lesion under direct visualization. Obtaining tissue sample from different areas of the pancreatic lesion is recommended by inserting the needle in a fanning fashion to maximise the yield of biopsy. ${ }^{66}{ }^{67}$ Inserting FNA needle to target lesion closer to EUS probe is recommended for technical feasibility as the trajectory of needle may not be modified for distant lesions. ${ }^{68}{ }^{69}$ Although there is a risk of needle tract seeding with EUS-FNA, this is often not a concern when the subsequent surgical management includes resection of the pancreatic head. ${ }^{70}$

\section{Safety}

EUS-FNA confers several advantages in the evaluation of pancreatic masses including the ability to target small lesions due to high-resolution imaging in close proximity to the pancreas, less risk to puncturing the intervening organs, avoidance of needle tract tumor seeding and overall cost-effectiveness particularly by avoiding unnecessary additional procedures. The rate of EUS-FNAassociated complications such as pancreatitis, infection, intestinal perforation, biliary peritonitis and malignant seeding is low as compared with other modalities. ${ }^{65}$ The overall complication rate of EUS-FNA is $2.5 \%$ which ensures diagnostic safety of this approach. The risk of pancreatitis ranges from $0.3 \%$ to $0.9 \%$ with EUS-FNA which is significantly lower than ERCP-guided brush cytology $0 \%-21.5 \%$ and percutaneous biopsies $4 \% .{ }^{65} 71$ The risk of malignant peritoneal seeding is very low with EUS-FNA 2.2\% as compared with percutaneous biopsy $16.3 \% .^{72}$

\section{Accuracy}

The diagnostic accuracy of EUS-FNA is high for establishing a diagnosis of pancreatic malignancy. EUS-FNA yields an accuracy of $85 \%-92 \%$, sensitivity of $80 \%-95 \%$ and specificity of $92 \%-100 \%$ in diagnosing pancreatic malignancy. ${ }^{73-76}$ Several confounding factors such as tumor consistency, needle diameter, number of passes and availability of on-site cytopathologist can affect the diagnostic yield of EUS-FNA. Although the size of EUS-FNA needles varies from 19 to 25 gauge $(\mathrm{G})$, however, most endosonographers use either $25 \mathrm{G}$ or $22 \mathrm{G}$ needles with the dedicated acquisition of tissue for making diagnosis of malignant lesions. A meta-analysis showed a higher yield for $25 \mathrm{G}$ needles for diagnosis of pancreatic cancers with pooled sensitivity of $93 \%$ and specificity of $97 \%$ as compared with $22 \mathrm{G}$ needle with $85 \%$ sensitivity and $99 \%$ specificity. ${ }^{77}$ While there is conflicting information about 


\begin{tabular}{|c|c|c|c|c|c|}
\hline Study & $\begin{array}{l}\text { Year of } \\
\text { study }\end{array}$ & $\begin{array}{l}\text { Total no of } \\
\text { patients }\end{array}$ & $\begin{array}{l}\text { Accuracy/diagnostic yield, } \\
\text { FNA versus FNB (\%) }\end{array}$ & $\begin{array}{l}\text { Sensitivity, FNA } \\
\text { versus FNB (\%) }\end{array}$ & $\begin{array}{l}\text { Specificity, FNA } \\
\text { versus FNB (\%) }\end{array}$ \\
\hline Cheng et $a l^{80}$ & 2018 & 408 & 80 vs $91.4^{*}$ & NA & NA \\
\hline Van Riet et $a l^{82}$ & 2019 & 608 & 87 vs $78^{*}$ & 90 vs $82^{*}$ & 96 vs 91 \\
\hline Wang et $a l^{83}$ & 2016 & 408 & 80 vs 93 & NA & NA \\
\hline Vanbiervliet et $\left.a\right|^{81}$ & 2014 & 80 & 92.5 vs 90 & NA & NA \\
\hline Lee et $a l^{84}$ & 2014 & 118 & 94.8 vs 98.3 & 94.6 vs 98.2 & 100 vs 100 \\
\hline Strand et $a /^{85}$ & 2014 & 32 & 93.8 vs $28.1^{*}$ & NA & NA \\
\hline
\end{tabular}

*Statistically significant data.

EUS, endoscopic ultrasound; FNA, fine-needle aspiration; FNB, fine-needle biopsy; NA, not applicable; RCT, randomised control trial.

the yield of needle size, the added advantage of smaller gauge needles exhibit less risk of bleeding and easy penetration through desmoplastic tissues. The utilization of rapid on-site evaluation (ROSE) of cytology specimens has significantly reduced the need for multiple needle passed for making a diagnosis whereby the presence of an on-site cytopathologist advises about specimen adequacy and real-time diagnosis during the procedure. Multiple studies have shown an increase in the diagnostic yield of this approach by $10 \%-30 \%$ with an accuracy of $93.3 \%-96.8 \%$, sensitivity of $88.6 \%-96.2 \%$ and specificity of $99 \%-100 \% .^{78-81}$

\section{Endoscopic ultrasound fine needle biopsy \\ Indications}

Differentiating pancreatic malignancy from AIP, chronic pancreatitis and pancreatic lymphoma or tuberculosis may be challenging because EUS-FNA may not provide sufficient tissue for molecular and histological evaluation of malignancy. ${ }^{82}$ EUS-FNB provides core tissue with preserved architecture of desmoplastic stroma and glandular tissues to establish histological diagnosis of PDAC and to differentiate malignancy from AIP, chronic pancreatitis, pancreatic lymphoma or tuberculosis. In addition, it may provide additional tissue for molecular profiling (such as immunohistochemistry, DNA sequencing or RNA-based marker studies) and when morphological retention of tissue architecture is needed for establishing diagnosis and management.

\section{Technical feasibility considerations}

EUS-FNB is a technique similar to EUS-FNA to acquire tissue for histological evaluation. There are various types of FNB needles including a Fork tip, a Franseen tip and a side opening needle which are designed to obtain a core sample from the target tissue. The Fork tip needle design has an additional sharp tip while the Franseen needle has three cutting edges. A recent randomised control trial (RCT) and a meta-analysis on 21 studies showed no significant difference in diagnostic yield of Franseen tip needle $92.7 \%-94 \%$ as compared with Fork tip FNB needle $98 \% .^{83}$ Only one RCT showed higher diagnostic yield of 19G FNB needle $89.5 \%$, compared with 22G needle $82.5 \%$ and $25 \mathrm{G}$ needle $63 \%{ }^{85}$ The selection of FNB needle is based on cost of needle and physicians preference without compromising diagnostic accuracy of procedure.

\section{Safety}

The safety profile EUS-FNB is comparable with EUS-FNA. EUS-FNB appears to be a cost-effective approach, which provides adequate tissue sample with fewer needle passes to establish diagnosis. ${ }^{86}{ }^{87}$ Whereas initially EUS-FNB was being used as salvage procedure in case of unsatisfactory FNA sampling for making diagnosis, more recently FNB is replacing FNA for tissue acquisition and may completely eradicate the need for ROSE. ${ }^{87}$ A meta-analysis has shown pooled diagnostic yield of FNB without and with ROSE and found no difference between two approaches $95.9 \%$ vs $93.7 \%$, respectively. ${ }^{84}$ This approach may ultimately cut down the procedural time, hospital cost and minimise resource utilization.

\section{Accuracy}

The accuracy of EUS-FNB is promising in the diagnosis of pancreatic malignancy when higher tissue cellularity and core histological sample is required. A recent study showed 90\% accuracy of FNB using the Franseen biopsy needle. ${ }^{88}$ It provides a dedicated tissue sample for molecular profiling and preserves structural integrity for histological analysis. A multicentre RCT showed 91.4\% accuracy of FNB samples as compared with FNA sample $80 \%$ for the diagnosis of pancreatic masses, while no difference was found in the diagnostic yield of non-pancreatic masses. ${ }^{89}$ Another meta-analysis on 11 studies has shown higher accuracy of FNB (OR: 1.62) for diagnosis of solid pancreatic cancers as opposed to FNA. ${ }^{84}$ There was no difference in rate of complications and technical success between two approaches. Several RCTs have shown the superiority of FNB over FNA to diagnose pancreatic cancers while some RCT showed no difference in diagnostic accuracy, sensitivity and specificity between two techniques (table 2). ${ }^{89-94}$ 


\section{EUS-GUIDED THERAPEUTIC INTERVENTIONS \\ Endoscopic ultrasound-guided biliary drainage Indications}

In current practice, the most commonly used method for biliary drainage $(\mathrm{BD})$ in the setting of pancreatic malignancy is ERCP-guided drainage which typically shows an excellent success rate of over $90 \% .{ }^{95}$ BD with ERCP is challenging in cases of benign or malignant stricture of oesophagus or duodenum, anatomic or pathological abnormality of ampulla (such as malignant infiltration of ampulla or periampullary diverticulum), and in case of altered anatomy of gastrointestinal tract after bariatric gastric bypass surgeries. Due to difficult access to the ampulla, percutaneous transhepatic BD (PTBD) or surgical decompression are alternative procedures of choice after failed ERCP. The associated morbidities (such as risk of bleeding, infections, cholangitis, pancreatitis, catheter dislocation and bile leak) are high with these procedures (up to 33\%). ${ }^{96}{ }^{97}$ The failure rate of ERCP BD is $3 \%-10 \%$ specifically due to ampullary infiltration of pancreatic cancers. ${ }^{98}$ Currently, there is increasing use of EUS-BD in these patients. ${ }^{98}$

\section{Technical feasibility considerations}

EUS-BD can be performed with either intrahepatic or extrahepatic techniques depending on the patient's anatomy and technical feasibility. The intrahepatic techniques are EUS-guided hepaticogastrostomy with antegrade stent placement where the tip of EUS scope is positioned along the lesser curvature of the stomach to visualize dilated left hepatic duct. Under EUS and fluoroscopic guidance, a 19-22 G transgastric needles inserted into the lumen of the left hepatic duct. The needle track is dilated over the guidewire with a $6.5 \mathrm{Fr}$ cystotome to create a hepatogastric fistula and a fully covered self-expanding metal stent or lumen apposing metal stent (LAMS) can be placed for biliary decompression. A transpapillary stent could be deployed with antegrade advancement of the wire or with an EUS-guided rendezvous (EUS-RV) technique. In EUS-RV, a dilated biliary duct is punctured with a $19 \mathrm{G}$ needle, the guidewire is advanced through needle into duodenal lumen in an antegrade fashion and finally, retrograde cannulation of common bile duct (CBD) is performed with ERCP duodenoscope using the EUS directed guidewire. ${ }^{95} 99$ The extrahepatic techniques include EUS-guided choledochoduodenostomy where the dilated CBD can be visualized by positioning tip of EUS scope in the duodenal bulb or antrum. After inserting a $19 \mathrm{G}$ transduodenal needle into CBD, needle track is created over 0.035inch guidewire and transluminal or transpapillary stent is deployed. ${ }^{95} 99$ Metal stent are preferred over plastic stents due to better safety profile, less risk of stent-related complications. ${ }^{100}$

\section{Safety}

EUS-BD is an emerging technique with both technical and functional success rate over $90 \% .^{101102}$ The technical and clinical success rates of EUS-BD and ERCP-BD are comparable, however, the advantages of EUS-BD over ERCP-BD are lower adverse outcomes with low risk of postprocedure pancreatitis, longer stent patency with decreased reintervention need and increased quality of life. ${ }^{37103104}$ After failed ERCP, EUS-BD is a promising salvage technique due to high technical feasibility and low risk of complications compared with PTBD and surgical biliary decompression. The overall reported risk of complications due to EUS-BD is $5 \%-10 \% .{ }^{101} \mathrm{~A}$ meta-analysis on 42 studies showed complications associated with EUS-BD are bile leakage $4.03 \%$, haemorrhage $4.03 \%$, perforation $3.02 \%$, migration of stent $2.68 \%$, infections $1.26 \%-2.43 \%$ and postprocedure pain $1.51 \%{ }^{100} 102105106$ The utility of metal stents has significantly reduced stent-related complications of $\mathrm{BD}$. When comparing intrahepatic with extrahepatic biliary decompression, there is no difference in success rate $(90.4 \%$ vs $84.3 \%)$ and overall outcome $(32.6 \%$ vs $35.6 \%)$ between two approaches. ${ }^{106}$

\section{Accuracy}

The efficacy and technical success rate of EUS-BD is improving. The rate of complications can be reduced by performing this procedure in expert centres. The long learning curve of this technique is directly associated with low rates of complications and high success rate. ${ }^{101107108} \mathrm{~A}$ group of 40 international experts suggested that EUS-BD should be performed by an expert endoscopist who master the EUS and ERCP techniques and has at least 4-5 years of experience (approximately 200-300 EUS and ERCP annually) with success rate over $95 \%$ for standard ERCP. ${ }^{109}$ Currently, there are no significant data on the accuracy of EUS-BD due to limited use of this technique as ERCP-BD is still the first-line procedure of choice for biliary decompression whenever possible. Further RCTs are required to determine further safety and accuracy of EUS-BD. The selection of intrahepatic or extrahepatic techniques is based on the patient's clinical presentation, anatomical location of pathologic lesions and preference of endoscopist.

\section{Endoscopic ultrasound-fine needle injection Indications}

EUS-fine needle injection (FNI) is a rapidly emerging technique to deliver implants and injections into pancreatic lesions under direct EUS visualization. The preoperative EUS-guided injection of dyes to tattoo tumor is increasingly used for localization of operable pancreatic lesions. EUS-guided implantation of fiducial markers into the tumor enables targeted radiation therapy to the pancreatic tumors. Similarly, the direct injection of certain antitumor agents into the tumor may provide localized chemotherapy. The advantage of localised chemotherapy is to expose targeted lesion with high concentration of chemotherapeutic agents while minimising the risk of systemic toxicities. ${ }^{110}$ 
Technical feasibility considerations

A $19 \mathrm{G}$ or $22 \mathrm{G}$ fine needle is inserted into the targeted lesions under direct EUS visualization. EUS-guided fine needle tattooing (EUS-FNT) is usually performed by injecting $2-5 \mathrm{~mL}$ sterile dye (carbon particles, indocyanine or India ink) into normal pancreatic tissue $2 \mathrm{~cm}$ away from tumor margins. ${ }^{111} 112$ A number of EUS-FNI agents, including ethanol, antitumor adenovirus vector (ONYX-015, TNFerade,), antitumor therapy (dendritic cells), gemcitabine, paclitaxel, have been experimentally used in humans with similar techniques. Additionally, EUS-guided placement of fiducial markers directly into pancreatic tumors, may be useful in radiation treatment planning.

\section{Safety and accuracy}

EUS-FNI is a very safe and minimally invasive method for both therapeutic and diagnostic interventions in the management of pancreatic cancers. The advantage of preoperative EUS-FNT is accurate identification of small pancreatic tumors during surgical resection which results in limited resection of pancreatic tissue, shorter operative time and fewer surgical complications. ${ }^{112}$ The technical success rate of EUS-brachytherapy (placement of radioactive seeds directly into the pancreas) is $85 \%-100 \% .^{113} 114$ EUS-guided brachytherapy, have shown an improvement in pain symptoms but not overall survival. ${ }^{110} 115116$

\section{EUS-guided celiac plexus neurolysis and celiac plexus block} The injection of nerve-blocking agents using the celiac plexus neurolysis $(\mathrm{CPN})$ plays an important role in the management of palliative pain in unresectable pancreatic cancers.

\section{Indications}

Pain management in pancreatic cancers is sometimes challenging in cases of inadequate pain control with nonnarcotic medications and contraindications to opioid therapy. EUS-guided CPN is a well-accepted nonpharmacological treatment option for pain management to improve quality of life. In patients with unresectable pancreatic cancers, EUS-CPN is associated with better pain control and reduction in the consumption of opioids. ${ }^{117}$

\section{Technical feasibility considerations}

The celiac plexus is located below the diaphragm adjacent to the anterolateral aspect of the celiac trunk. EUS identifies the location of the celiac plexus at the junction between the celiac trunk and aorta. There are two types of endoscopic approaches for performing CPN including 'central' and 'bilateral' techniques. A linear echoendoscope is positioned in the body of the stomach to identify abdominal aorta. The echoendoscope traces the aorta down to the celiac trunk. In the central approach, the needle is directed centrally at the junction of aorta and the celiac artery. In the bilateral approach, the echoendoscope is rotated clockwise to advance the needle adjacent to the celiac artery to the point of origin of SMA from aorta. A $10 \mathrm{~mL}$ of $0.25 \%$ bupivacaine is injected adjacent and anterior to the celiac artery depending on abovementioned approaches. This is followed by the injection of neurolytic agents either $10 \mathrm{~mL}$ of dehydrated $98 \%$ alcohol or phenol. A dedicated $20 \mathrm{G}$ needle with multiple side holes assists in the effective spread of injecting agents into the celiac plexus is available. The needle should be flushed with $3 \mathrm{~mL}$ of normal saline before withdrawal to prevent postprocedural abdominal pain secondary to the seeding of neurolytic agent in the needle track.

\section{Safety and accuracy}

EUS-guided CPN is a relatively safe alternative than CT or fluoroscopically guided plexus neurolysis in the management of pancreatic cancer pain. A meta-analysis on pain management in pancreatic cancer patients showed a longterm success rate of $72 \%$ with EUS-CPN and is a reasonable option for patients with tolerance to narcotic analgesics. ${ }^{118}$ Another meta-analyses including 17 studies have shown $80.12 \%$ pooled pain relief related to pancreatic cancers with EUS-CPN techniques. ${ }^{119}$ The pain-relieving effect of the bilateral technique is long-lasting and much higher $84.54 \%$ than central technique $45.99 \% .{ }^{119}$ Overall EUS-CPN and EUS-celiac plexus block (CPB) are safe, and effective palliative methods in pancreatic cancers which allow the patients to cut-down their narcotics and improve their pain control. Moreover, the injection on both sides of the celiac artery had a higher pain-relieving success rate compared with injection on one side $(85 \%$ vs $46 \%)$. The reported rate of complications is $2 \%-7 \%$ with EUS-CPB while up to $21 \%$ with EUS-CPN which is relatively lower than other modalities. ${ }^{120}$ The most common transient complications are local pain $(36 \%)$, hypotension $(33 \%)$ and diarrhea $(23.4 \%) .{ }^{120} 121$

\section{Role of EUS in gastric outlet obstruction}

\section{Indications}

Pancreatic cancers are associated with gastric outlet obstruction (GOO) in approximately 10\%-20\% patients. ${ }^{122} 123$ The progression of primary pancreatic tumor causes GOO due to extrinsic duodenal compression in most cases. Nausea, nonbilious vomiting, symptoms of malnutrition and dehydration are the initial symptoms of GOO. The quality of life in these patients is poor due to malnourishment and pancreatic cancer pain. The goal of palliative treatment is to relieve symptoms of GOO and improve nutritional status. Typically, palliative treatment of malignant GOO has been performed with established methods including open or laparoscopic surgical gastrojejunostomy (GJ) and duodenal stenting. Recently established minimal invasive endoscopic techniques including EUS-GJ are novel and promising modalities in the management of GOO.

\section{Technical feasibility considerations}

EUS-GJ is technically challenging than conventional duodenal stenting and should be performed by the expert therapeutic endoscopist. In the direct 
EUS-gastroenterostomy (GE) approach, a therapeutic forward-viewing echoendoscope is used to fill small bowel with mixture of saline, contrast and methylene blue. A transgastric $19 \mathrm{G}$ needle is used to puncture small bowel distal to GOO. The needle position is confirmed with the aspiration of blue-tinged fluid and enterogram. After withdrawing the needle, a cautery assisted LAMS is deployed across small bowel and gastric body. ${ }^{124} \mathrm{~A}$ balloon-assisted GE is another approach of EUS-GJ in which a guide-wire is placed across the GOO, followed by inflation of the balloon with contrast fluid. The contrast filled balloon is then punctured with EUS-guided $19 \mathrm{G}$ needle transgastrically. A guidewire is then advanced into small bowel followed by deployment of LAMS to create gastroenterostomy. ${ }^{124}$

\section{Safety and accuracy}

EUS-GJ is a safe modality in the management of malignant GOO. These minimally invasive techniques offer the potential benefits of surgical bypass with higher technical success $(90 \%-100 \%)$, clinical success rates $(80 \%-95 \%)$ and low risk of adverse events or procedural complications. ${ }^{124-128}$ The reported complications of EUS-GJ are perforation, peritonitis, haemorrhage and luminal obstruction of the stent due to food impaction. EUS-GE should be avoided in patients with perigastric varices and those with massive ascites due to increased risk of bleeding, peritonitis and leakage or anastomotic dehiscence. A recent meta-analysis including 12 studies showed adverse events in $12 \%$ of patients while $9 \%$ of patients showed recurrent symptoms requiring reintervention. ${ }^{128}$

\section{Conclusion}

EUS plays an important role in the evaluation of pancreatic masses and in determination of the accurate stage of pancreatic cancers by providing cytological and histological confirmation. Additionally, EUS-guided therapeutic interventions are promising modalities providing effective BD particularly in individuals where ERCP is not feasible. Further RCTs are needed to establish further validations of newer endoscopic techniques for the management of pancreatic malignancy.

Twitter Muhammad Nadeem Yousaf @M_Nadeem_Yousaf

Contributors MNY: Manuscript writing and overall data collection. FSC, AE, ALS, TM, PJ andHRA: Review of manuscript and data and proofreading. JF: Manuscript supervision.

Funding The authors have not declared a specific grant for this research from any funding agency in the public, commercial or not-for-profit sectors.

Competing interests None declared.

Patient consent for publication Not required.

Provenance and peer review Commissioned; externally peer reviewed.

Data availability statement Data are available in a public, open access repository. This is a review article and all data are available online.

Open access This is an open access article distributed in accordance with the Creative Commons Attribution Non Commercial (CC BY-NC 4.0) license, which permits others to distribute, remix, adapt, build upon this work non-commercially, and license their derivative works on different terms, provided the original work is properly cited, appropriate credit is given, any changes made indicated, and the use is non-commercial. See: http://creativecommons.org/licenses/by-nc/4.0/.

ORCID iD

Muhammad Nadeem Yousaf http://orcid.org/0000-0002-7979-8929

\section{REFERENCES}

1 Siegel RL, Miller KD, Jemal A. Cancer statistics, 2018. CA Cancer J Clin 2018;68:7-30.

2 Ilic M, Ilic I. Epidemiology of pancreatic cancer. World J Gastroenterol 2016;22:9694-705.

3 Parkin DM, Boyd L, Walker LC. 16. The fraction of cancer attributable to lifestyle and environmental factors in the UK in 2010. Br J Cancer 2011;105 Suppl 2:S77-81.

4 Willett WC. Diet and cancer. Oncologist 2000;5:393-404

5 Bosetti C, Bertuccio P, Negri E, et al. Pancreatic cancer: overview of descriptive epidemiology. Mol Carcinog 2012;51:3-13.

6 Sant M, Aareleid T, Berrino F, et al. EUROCARE-3: survival of cancer patients diagnosed 1990-94--results and commentary. Ann Oncol 2003;14 Suppl 5:v61-118.

7 Coleman MP, Forman D, Bryant $\mathrm{H}$, et al. Cancer survival in Australia, Canada, Denmark, Norway, Sweden, and the UK, 1995-2007 (the International cancer benchmarking partnership): an analysis of population-based cancer registry data. Lancet $2011 ; 377: 127-38$

8 Siegel RL, Miller KD, Jemal A. Cancer statistics, 2016. CA Cancer J Clin 2016;66:7-30.

9 DeWitt J, Devereaux B, Chriswell M, et al. Comparison of endoscopic ultrasonography and multidetector computed tomography for detecting and staging pancreatic cancer. Ann Intern Med 2004;141:753-63.

10 Peters MLB, Eckel A, Mueller PP, et al. Progression to pancreatic ductal adenocarcinoma from pancreatic intraepithelial neoplasia: results of a simulation model. Pancreatology 2018;18:928-34.

11 Unger K, Mehta KY, Kaur P, et al. Metabolomics based predictive classifier for early detection of pancreatic ductal adenocarcinoma. Oncotarget 2018;9:23078-90.

12 Canto Ml, Harinck F, Hruban $\mathrm{RH}$, et al. International cancer of the pancreas screening (CAPS) Consortium Summit on the management of patients with increased risk for familial pancreatic cancer. Gut 2013;62:339-47.

13 Chari ST, Kelly K, Hollingsworth MA, et al. Early detection of sporadic pancreatic cancer: summative review. Pancreas 2015;44:693-712.

14 , Eloubeidi MA, Decker GA, et al, ASGE Standards of Practice Committee. The role of endoscopy in the evaluation and management of patients with solid pancreatic neoplasia. Gastrointest Endosc 2016;83:17-28.

15 Tanaka M, Fernández-Del Castillo C, Kamisawa T, et al. Revisions of international consensus Fukuoka guidelines for the management of IPMN of the pancreas. Pancreatology 2017;17:738-53.

16 Vege SS, Ziring B, Jain R, et al. American gastroenterological association Institute guideline on the diagnosis and management of asymptomatic neoplastic pancreatic cysts. Gastroenterology 2015;148:819-22

17 Du C, Chai N-L, Linghu E-Q, et al. Comparison of endoscopic ultrasound, computed tomography and magnetic resonance imaging in assessment of detailed structures of pancreatic cystic neoplasms. World J Gastroenterol 2017;23:3184-92.

18 Kamata K, Kitano M, Kudo M, et al. Value of EUS in early detection of pancreatic ductal adenocarcinomas in patients with intraductal papillary mucinous neoplasms. Endoscopy 2014;46:22-9.

19 Kitano M, Kudo M, Yamao K, et al. Characterization of small solid tumors in the pancreas: the value of contrast-enhanced harmonic endoscopic ultrasonography. Am J Gastroenterol 2012;107:303-10.

20 Sakamoto H, Kitano M, Suetomi Y, et al. Utility of contrastenhanced endoscopic ultrasonography for diagnosis of small pancreatic carcinomas. Ultrasound Med Biol 2008;34:525-32.

21 Jemaa Y, Houissa F, Trabelsi S, et al. Endoscopic ultrasonography versus helical $\mathrm{CT}$ in diagnosis and staging of pancreatic cancer. Tunis Med 2008;86:346-9.

22 Kitano M, Kudo M, Maekawa K, et al. Dynamic imaging of pancreatic diseases by contrast enhanced coded phase inversion harmonic ultrasonography. Gut 2004;53:854-9.

23 Agarwal B, Abu-Hamda E, Molke KL, et al. Endoscopic ultrasound-guided fine needle aspiration and multidetector spiral $\mathrm{CT}$ in the diagnosis of pancreatic cancer. Am J Gastroenterol 2004;99:844-50. 
24 Rivadeneira DE, Pochapin M, Grobmyer SR, et al. Comparison of linear array endoscopic ultrasound and helical computed tomography for the staging of periampullary malignancies. Ann Surg Oncol 2003;10:890-7.

25 Mertz HR, Sechopoulos P, Delbeke D, et al. EUS, PET, and CT scanning for evaluation of pancreatic adenocarcinoma. Gastrointest Endosc 2000;52:367-71.

26 Gress FG, Hawes RH, Savides TJ, et al. Role of EUS in the preoperative staging of pancreatic cancer: a large single-center experience. Gastrointest Endosc 1999;50:786-91.

27 Harrison JL, Millikan KW, Prinz RA, et al. Endoscopic ultrasound for diagnosis and staging of pancreatic tumors. Am Surg 1999;65:659-64

28 Midwinter MJ, Beveridge CJ, Wilsdon JB, et al. Correlation between spiral computed tomography, endoscopic ultrasonography and findings at operation in pancreatic and ampullary tumours. Br J Surg 1999;86:189-93.

29 Legmann P, Vignaux O, Dousset B, et al. Pancreatic tumors: comparison of Dual-phase helical CT and endoscopic sonography. AJR Am J Roentgenol 1998;170:1315-22.

30 Sugiyama M, Hagi H, Atomi Y, et al. Diagnosis of portal venous invasion by pancreatobiliary carcinoma: value of endoscopic ultrasonography. Abdom Imaging 1997;22:434-8.

31 Howard TJ, Chin AC, Streib EW, et al. Value of helical computed tomography, angiography, and endoscopic ultrasound in determining resectability of periampullary carcinoma. Am J Surg 1997;174:237-41.

32 Melzer E, Avidan B, Heyman Z, et al. Preoperative assessment of blood vessel involvement in patients with pancreatic cancer. Isr J Med Sci 1996;32:1086-8.

33 Nakaizumi A, Uehara $\mathrm{H}$, lishi $\mathrm{H}$, et al. Endoscopic ultrasonography in diagnosis and staging of pancreatic cancer. Dig Dis Sci 1995;40:696-700.

34 Marty O, Aubertin JM, Bouillot JL, et al. [Prospective comparison of ultrasound endoscopy and computed tomography in the assessment of locoregional invasiveness of malignant ampullar and pancreatic tumors verified surgically]. Gastroenterol Clin Biol 1995:19:197-203.

35 Müller MF, Meyenberger C, Bertschinger P, et al. Pancreatic tumors: evaluation with endoscopic us, CT, and MR imaging. Radiology 1994;190:745-51.

36 Bang JY, Navaneethan U, Hasan M, et al. Stent placement by EUS or ERCP for primary biliary decompression in pancreatic cancer: a randomized trial (with videos). Gastrointest Endosc 2018;88:9-17.

37 Palazzo L, Roseau G, Gayet B, et al. Endoscopic ultrasonography in the diagnosis and staging of pancreatic adenocarcinoma. Results of a prospective study with comparison to ultrasonography and CT scan. Endoscopy 1993;25:143-50.

38 Yasuda K, Mukai H, Nakajima M, et al. Staging of pancreatic carcinoma by endoscopic ultrasonography. Endoscopy 1993;25:151-5.

39 Rösch T, Lorenz R, Braig C, et al. Endoscopic ultrasound in pancreatic tumor diagnosis. Gastrointest Endosc 1991;37:347-52.

40 He X-K, Ding Y, Sun L-M. Contrast-Enhanced endoscopic ultrasound for differential diagnosis of pancreatic cancer: an updated meta-analysis. Oncotarget 2017;8:66392-401.

41 Sarno A, Tedesco G, De Robertis R, et al. Pancreatic cystic neoplasm diagnosis: role of imaging. Endosc Ultrasound 2018;7:297-300.

42 Canto MI, Hruban RH, Fishman EK, et al. Frequent detection of pancreatic lesions in asymptomatic high-risk individuals. Gastroenterology 2012;142:796-804.

43 Das KK, Early D. Pancreatic cancer screening. Curr Treat Options Gastroenterol 2017;15:562-575.

44 Eshleman JR, Norris AL, Sadakari Y, et al. Kras and guanine nucleotide-binding protein mutations in pancreatic juice collected from the duodenum of patients at high risk for neoplasia undergoing endoscopic ultrasound. Clin Gastroenterol Hepatol 2015;13:963-9.

45 Kanda M, Knight S, Topazian M, et al. Mutant Gnas detected in duodenal collections of secretin-stimulated pancreatic juice indicates the presence or emergence of pancreatic cysts. Gut 2013;62:1024-33.

46 Tanaka M, Heckler M, Liu B, et al. Cytologic analysis of pancreatic juice increases specificity of detection of malignant IPMN-A systematic review. Clin Gastroenterol Hepatol 2019;17:2199-211.

47 European Study Group on Cystic Tumours of the Pancreas. European evidence-based guidelines on pancreatic cystic neoplasms. Gut 2018;67:789-804.

48 Kongkam P, Ang TL, Vu CKF, et al. Current status on the diagnosis and evaluation of pancreatic tumor in Asia with particular emphasis on the role of endoscopic ultrasound. J Gastroenterol Hepatol 2013;28:924-30.

49 Perez-Johnston R, Sainani NI, Sahani DV. Imaging of chronic pancreatitis (including groove and autoimmune pancreatitis). Radiol Clin North Am 2012;50:447-66.

50 Brand B, Pfaff T, Binmoeller KF, et al. Endoscopic ultrasound for differential diagnosis of focal pancreatic lesions, confirmed by surgery. Scand J Gastroenterol 2000;35:1221-8.

51 Dewitt J, Devereaux BM, Lehman GA, et al. Comparison of endoscopic ultrasound and computed tomography for the preoperative evaluation of pancreatic cancer: a systematic review. Clin Gastroenterol Hepatol 2006;4:717-25.

52 Zhang $\mathrm{Y}$, Huang J, Chen $\mathrm{M}$, et al. Preoperative vascular evaluation with computed tomography and magnetic resonance imaging for pancreatic cancer: a meta-analysis. Pancreatology 2012;12:227-33.

53 Chaudhary V, Bano S. Imaging of the pancreas: recent advances. Indian J Endocrinol Metab 2011;15:S25-32.

54 Rafique A, Freeman S, Carroll N. A clinical algorithm for the assessment of pancreatic lesions: utilization of 16- and 64-section multidetector CT and endoscopic ultrasound. Clin Radiol 2007;62:1142-53.

55 Korc P, Sherman S. Ercp tissue sampling. Gastrointest Endosc 2016;84:557-71.

56 Savides TJ. Tricks for improving EUS-FNA accuracy and maximizing cellular yield. Gastrointest Endosc 2009;69:S130-3.

57 Varadarajulu S, Bang JY, Hebert-Magee S. Assessment of the technical performance of the flexible 19-gauge EUS-FNA needle. Gastrointest Endosc 2012;76:336-43.

58 Artifon ELA, Guedes HG, Cheng S. Maximizing the diagnostic yield of endoscopic ultrasound-guided fine-needle aspiration biopsy. Gastroenterology 2017;153:881-5.

59 Yousaf MN, Cai G, Aslanian HR. EUS evaluation of liver lesions. VideoGIE 2018;3:31-3

60 Minaga K, Takenaka M, Katanuma A, et al. Needle tract seeding: an overlooked rare complication of endoscopic ultrasound-guided fine-needle aspiration. Oncology 2017;93 Suppl 1:107-12.

61 Eloubeidi MA, Tamhane A, Varadarajulu S, et al. Frequency of major complications after EUS-guided FNA of solid pancreatic masses: a prospective evaluation. Gastrointest Endosc 2006;63:622-9.

62 Micames C, Jowell PS, White R, et al. Lower frequency of peritoneal carcinomatosis in patients with pancreatic cancer diagnosed by EUS-guided FNA vs. percutaneous FNA. Gastrointest Endosc 2003;58:690-5

63 Hewitt MJ, McPhail MJW, Possamai L, et al. EUS-guided FNA for diagnosis of solid pancreatic neoplasms: a meta-analysis. Gastrointest Endosc 2012;75:319-31.

64 Puli SR, Bechtold ML, Buxbaum JL, et al. How good is endoscopic ultrasound-guided fine-needle aspiration in diagnosing the correct etiology for a solid pancreatic mass?: a meta-analysis and systematic review. Pancreas 2013;42:20-6.

65 Raut CP, Grau AM, Staerkel GA, et al. Diagnostic accuracy of endoscopic ultrasound-guided fine-needle aspiration in patients with presumed pancreatic cancer. J Gastrointest Surg 2003;7:118-28.

66 Mohammad Alizadeh AH, Shahrokh S, Hadizadeh M, et al. Diagnostic potency of EUS-guided FNA for the evaluation of pancreatic mass lesions. Endosc Ultrasound 2016:5:30-4.

67 Madhoun MF, Wani SB, Rastogi A, et al. The diagnostic accuracy of 22-gauge and 25-gauge needles in endoscopic ultrasound-guided fine needle aspiration of solid pancreatic lesions: a meta-analysis. Endoscopy 2013;45:86-92

68 Itoi T, Tsuchiya T, Itokawa F, et al. Histological diagnosis by EUSguided fine-needle aspiration biopsy in pancreatic solid masses without on-site cytopathologist: a single-center experience. Dig Endosc 2011;23 Suppl 1:34-8.

69 Hébert-Magee S, Bae S, Varadarajulu S, et al. The presence of a cytopathologist increases the diagnostic accuracy of endoscopic ultrasound-guided fine needle aspiration cytology for pancreatic adenocarcinoma: a meta-analysis. Cytopathology 2013;24:159-71.

70 Iglesias-Garcia J, Dominguez-Munoz JE, Abdulkader I, et al. Influence of on-site cytopathology evaluation on the diagnostic accuracy of endoscopic ultrasound-guided fine needle aspiration (EUS-FNA) of solid pancreatic masses. Am J Gastroenterol 2011;106:1705-10.

71 Koul A, Baxi AC, Shang R, et al. The efficacy of rapid on-site evaluation during endoscopic ultrasound-guided fine needle aspiration of pancreatic masses. Gastroenterol Rep 2018;6:45-8.

72 van Heerde MJ, Biermann K, Zondervan PE, et al. Prevalence of autoimmune pancreatitis and other benign disorders in 
pancreatoduodenectomy for presumed malignancy of the pancreatic head. Dig Dis Sci 2012;57:2458-65.

73 de la Fuente SG, Ceppa EP, Reddy SK, et al. Incidence of benign disease in patients that underwent resection for presumed pancreatic cancer diagnosed by endoscopic ultrasonography (EUS) and fineneedle aspiration (FNA). J Gastrointest Surg 2010;14:1139-42.

74 Bang JY, Hebert-Magee S, Navaneethan U, et al. Randomized trial comparing the Franseen and Fork-tip needles for EUS-guided fine-needle biopsy sampling of solid pancreatic mass lesions. Gastrointest Endosc 2018;87:1432-8.

75 Mohan BP, Shakhatreh M, Garg R, et al. Comparison of Franseen and fork-tip needles for EUS-guided fine-needle biopsy of solid mass lesions: a systematic review and meta-analysis. Endosc Ultrasound 2019;8:382-391.

76 Panic N, Larghi A. Techniques for endoscopic ultrasoundguided fine-needle biopsy. Gastrointest Endosc Clin N Am 2014;24:83-107.

77 Bang JY, Hawes R, Varadarajulu S. A meta-analysis comparing procore and standard fine-needle aspiration needles for endoscopic ultrasound-guided tissue acquisition. Endoscopy 2016;48:339-49.

78 Rodrigues-Pinto E, Grimm IS, Baron TH. Endoscopic ultrasound fine-needle aspiration vs. fine-needle biopsy: tissue is always the issue. Endosc Int Open 2016;4:E506-7.

79 Bang JY, Hebert-Magee S, Navaneethan U, et al. EUS-guided fine needle biopsy of pancreatic masses can yield true histology. Gut 2018;67:2081.

80 Cheng B, Zhang Y, Chen Q, et al. Analysis of fine-needle biopsy vs fine-needle aspiration in diagnosis of pancreatic and abdominal masses: a prospective, multicenter, randomized controlled trial. Clin Gastroenterol Hepatol 2018;16:1314-21.

81 Vanbiervliet G, Napoléon B, Saint Paul MC, et al. Core needle versus standard needle for endoscopic ultrasound-guided biopsy of solid pancreatic masses: a randomized crossover study. Endoscopy 2014;46:1063-70.

82 van Riet PA, Larghi A, Attili F, et al. A multicenter randomized trial comparing a 25-gauge EUS fine-needle aspiration device with a 20-gauge EUS fine-needle biopsy device. Gastrointest Endosc 2019;89:329-339.

83 Wang J, Wu X, Yin P, et al. Comparing endoscopic ultrasound (EUS)-guided fine needle aspiration (FNA) versus fine needle biopsy (FNB) in the diagnosis of solid lesions: study protocol for a randomized controlled trial. Trials 2016;17:198.

84 Lee YN, Moon JH, Kim HK, et al. Core biopsy needle versus standard aspiration needle for endoscopic ultrasound-guided sampling of solid pancreatic masses: a randomized parallel-group study. Endoscopy 2014;46:1056-62.

85 Strand DS, Jeffus SK, Sauer BG, et al. EUS-guided 22-gauge fineneedle aspiration versus core biopsy needle in the evaluation of solid pancreatic neoplasms. Diagn Cytopathol 2014;42:751-8.

86 Kitano M, Kamata K, Imai H, et al. Contrast-Enhanced harmonic endoscopic ultrasonography for pancreatobiliary diseases. Dig Endosc 2015;27 Suppl 1:60-7.

87 Dietrich CF, Braden B, Hocke M, et al. Improved characterisation of solitary solid pancreatic tumours using contrast enhanced transabdominal ultrasound. J Cancer Res Clin Oncol 2008;134:635-43.

88 Mohamed RM, Yan BM. Contrast enhanced endoscopic ultrasound: more than just a fancy Doppler. World J Gastrointest Endosc 2010;2:237-43.

89 Becker D, Strobel D, Bernatik T, et al. Echo-enhanced colorand power-Doppler EUS for the discrimination between focal pancreatitis and pancreatic carcinoma. Gastrointest Endosc 2001;53:784-9.

90 Hocke M, Menges M, Topalidis T, et al. Contrast-Enhanced endoscopic ultrasound in discrimination between benign and malignant mediastinal and abdominal lymph nodes. J Cancer Res Clin Oncol 2008;134:473-80.

91 Mei S, Wang M, Sun L. Contrast-Enhanced EUS for differential diagnosis of pancreatic masses: a meta-analysis. Gastroenterol Res Pract 2019;2019:9.

92 Hu D-M, Gong T-T, Zhu Q. Endoscopic ultrasound elastography for differential diagnosis of pancreatic masses: a meta-analysis. Dig Dis Sci 2013;58:1125-31.

93 Mei M, Ni J, Liu D, et al. EUS elastography for diagnosis of solid pancreatic masses: a meta-analysis. Gastrointest Endosc 2013;77:578-89.

94 Li X, Xu W, Shi J, et al. Endoscopic ultrasound elastography for differentiating between pancreatic adenocarcinoma and inflammatory masses: a meta-analysis. World J Gastroenterol 2013;19:6284-91.
95 Janssen J, Schlörer E, Greiner L. EUS elastography of the pancreas: feasibility and pattern description of the normal pancreas, chronic pancreatitis, and focal pancreatic lesions. Gastrointest Endosc 2007;65:971-8.

96 Hirche TO, Ignee A, Barreiros AP, et al. Indications and limitations of endoscopic ultrasound elastography for evaluation of focal pancreatic lesions. Endoscopy 2008;40:910-7.

97 Iwashita T, Doi S, Yasuda I. Endoscopic ultrasound-guided biliary drainage: a review. Clin J Gastroenterol 2014;7:94-102.

98 Yarmohammadi H, Covey AM. Percutaneous biliary interventions and complications in malignant bile duct obstruction. Chin Clin Oncol 2016:5:68

99 Nennstiel S, Weber A, Frick G, et al. Drainage-related complications in percutaneous transhepatic biliary drainage: an analysis over 10 years. J Clin Gastroenterol 2015;49:764-70.

100 Salerno R, Davies SEC, Mezzina N, et al. Comprehensive review on EUS-guided biliary drainage. World J Gastrointest Endosc 2019;11:354-64.

101 Khashab MA, Messallam AA, Penas I, et al. International multicenter comparative trial of transluminal EUS-guided biliary drainage via hepatogastrostomy vs. choledochoduodenostomy approaches. Endosc Int Open 2016;4:E175-81.

102 Poincloux L, Rouquette O, Buc E, et al. Endoscopic ultrasoundguided biliary drainage after failed ERCP: cumulative experience of 101 procedures at a single center. Endoscopy 2015;47:794-801.

103 Wang K, Zhu J, Xing L, et al. Assessment of efficacy and safety of EUS-guided biliary drainage: a systematic review. Gastrointest Endosc 2016;83:1218-27.

104 Paik WH, Lee TH, Park DH, et al. EUS-Guided biliary drainage versus ERCP for the primary palliation of malignant biliary obstruction: a multicenter randomized clinical trial. Am J Gastroenterol 2018;113:987-97.

105 Park JK, Woo YS, Noh DH, et al. Efficacy of EUS-guided and ERCP-guided biliary drainage for malignant biliary obstruction: prospective randomized controlled study. Gastrointest Endosc 2018;88:277-82.

106 Baars JE, Kaffes AJ, Saxena P. EUS-guided biliary drainage: a comprehensive review of the literature. Endosc Ultrasound 2018;7:4-9.

107 Gupta K, Perez-Miranda M, Kahaleh M, et al. Endoscopic ultrasound-assisted bile duct access and drainage: multicenter, long-term analysis of approach, outcomes, and complications of a technique in evolution. J Clin Gastroenterol 2014;48:80-7.

108 Vila JJ, Pérez-Miranda M, Vazquez-Sequeiros E, et al. Initial experience with EUS-guided cholangiopancreatography for biliary and pancreatic duct drainage: a Spanish national survey. Gastrointest Endosc 2012;76:1133-41.

109 Oh D, Park DH, Song TJ, et al. Optimal biliary access point and learning curve for endoscopic ultrasound-guided hepaticogastrostomy with transmural stenting. Therap Adv Gastroenterol 2017;10:42-53.

110 Kahaleh M, Artifon ELA, Perez-Miranda M, et al. Endoscopic ultrasonography guided biliary drainage: summary of Consortium meeting, may 7th, 2011, Chicago. World J Gastroenterol 2013;19:1372-9.

111 Verna EC, Dhar V. Endoscopic ultrasound-guided fine needle injection for cancer therapy: the evolving role of therapeutic endoscopic ultrasound. Therap Adv Gastroenterol 2008;1:103-9.

112 Lennon AM, Newman N, Makary MA, et al. EUS-guided tattooing before laparoscopic distal pancreatic resection (with video). Gastrointest Endosc 2010;72:1089-94.

113 Farrell JJ, Sherrod A, Parekh D. EUS-guided fine-needle tattooing for preoperative localization of early pancreatic adenocarcinoma. Gastrointest Endosc 2009;69:176-7.

114 DiMaio CJ, Nagula S, Goodman KA, et al. EUS-guided fiducial placement for image-guided radiation therapy in Gi malignancies by using a 22-gauge needle (with videos). Gastrointest Endosc 2010;71:1204-10.

115 Varadarajulu S, Trevino JM, Shen S, et al. The use of endoscopic ultrasound-guided gold markers in image-guided radiation therapy of pancreatic cancers: a case series. Endoscopy 2010;42:423-5.

116 Du Y-Q, Li Z-S, Jin Z-D. Endoscope-assisted brachytherapy for pancreatic cancer: from tumor killing to pain relief and drainage. $J$ Interv Gastroenterol 2011:1:23-7.

117 Jin Z, Du Y, Li Z, et al. Endoscopic ultrasonography-guided interstitial implantation of iodine 125-seeds combined with chemotherapy in the treatment of unresectable pancreatic carcinoma: a prospective pilot study. Endoscopy 2008;40:314-20.

118 Wyse JM, Carone M, Paquin SC et al. Randomized, double-blind, controlled trial of early endoscopic ultrasound-guided celiac plexus neurolysis to prevent pain progression in patients with newly 
diagnosed, painful, inoperable pancreatic cancer. J Clin Oncol 2011;29:3541-6.

119 Kaufman M, Singh G, Das S, et al. Efficacy of endoscopic ultrasound-guided celiac plexus block and celiac plexus neurolysis for managing abdominal pain associated with chronic pancreatitis and pancreatic cancer. J Clin Gastroenterol 2010;44:127-34.

120 Puli SR, Reddy JBK, Bechtold ML, et al. EUS-guided celiac plexus neurolysis for pain due to chronic pancreatitis or pancreatic cancer pain: a meta-analysis and systematic review. Dig Dis Sci 2009;54:2330-7.

121 Alvarez-Sánchez MV, Jenssen C, Faiss S, et al. Interventional endoscopic ultrasonography: an overview of safety and complications. Surg Endosc 2014;28:712-34.

122 Eisenberg E, Carr DB, Chalmers TC. Neurolytic celiac plexus block for treatment of cancer pain: a meta-analysis. Anesth Analg 1995;80:290-5.
123 Singh SM, Longmire WP, Reber HA. Surgical palliation for pancreatic cancer. The UCLA experience. Ann Surg 1990;212:132-9.

124 Gohil VB, Klapman JB. Endoscopic palliation of pancreatic cancer. Curr Treat Options Gastroenterol 2017;15:333-48.

125 Chen Y-I, James TW, Agarwal A, et al. EUS-guided gastroenterostomy in management of benign gastric outlet obstruction. Endosc Int Open 2018;6:E363-8.

126 Irani S, Baron TH, Itoi T, et al. Endoscopic gastroenterostomy: techniques and review. Curr Opin Gastroenterol 2017;33:320-9.

127 Itoi T, Ishii K, Ikeuchi N, et al. Prospective evaluation of endoscopic ultrasonography-guided double-balloon-occluded gastrojejunostomy bypass (EPASS) for malignant gastric outlet obstruction. Gut 2016;65:193-5.

128 Tringali A, Giannetti A, Adler DG. Endoscopic management of gastric outlet obstruction disease. Ann Gastroenterol 2019;32:330-7. 